\title{
Room-Temperature Synthesis of Curved Ammonium Copper Molybdate Nanoflake and Its Hierarchical Architecture
}

\author{
Jiasheng $\mathrm{Xu}^{\mathrm{a}}$, Dongfeng Xue ${ }^{\mathrm{a}, *}$, and Yingchun Zhu ${ }^{\mathrm{b}}$ \\ ${ }^{a}$ State Key Laboratory of Fine Chemicals, Department of Materials Science and Chemical \\ Engineering, School of Chemical Engineering, Dalian University of Technology, 158 \\ Zhongshan Road, Dalian 116012, China \\ *Corresponding author. E-mail: dfxue@ chem.dlut.edu.cn \\ ${ }^{\mathrm{b}}$ Shanghai Institute of Ceramics, Chinese Academy of Sciences, 1295 Dingxi Road, \\ Shanghai 200050, China
}

\section{Supporting Information}




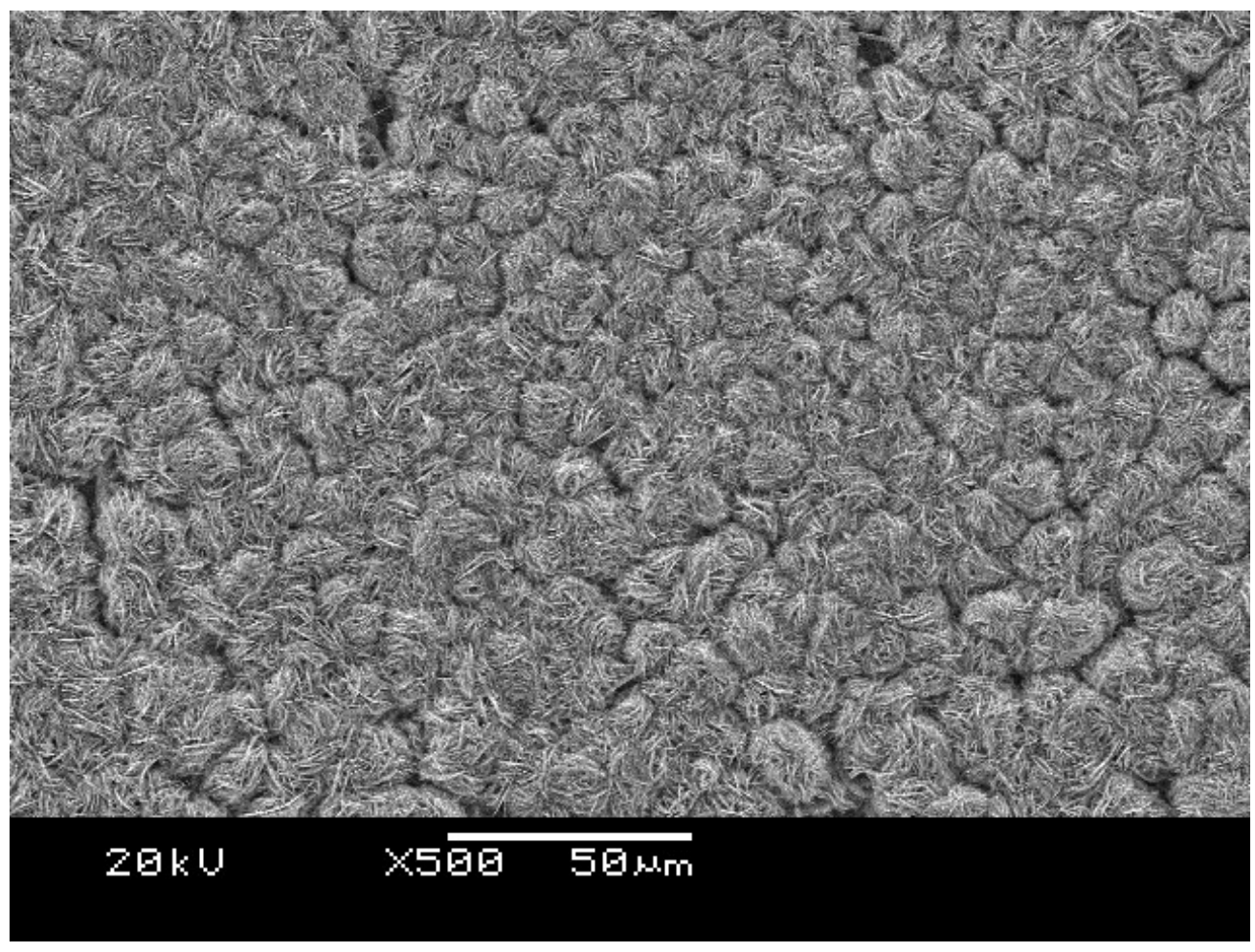

Figure S1. SEM image of $\left(\mathrm{NH}_{4}\right)_{2} \mathrm{Cu}\left(\mathrm{MoO}_{4}\right)_{2}$ crystals on the copper substrate with a high surface coverage (experimental conditions are the same as those shown in Figure 3), which is a large-scale observation of Figure 3. 

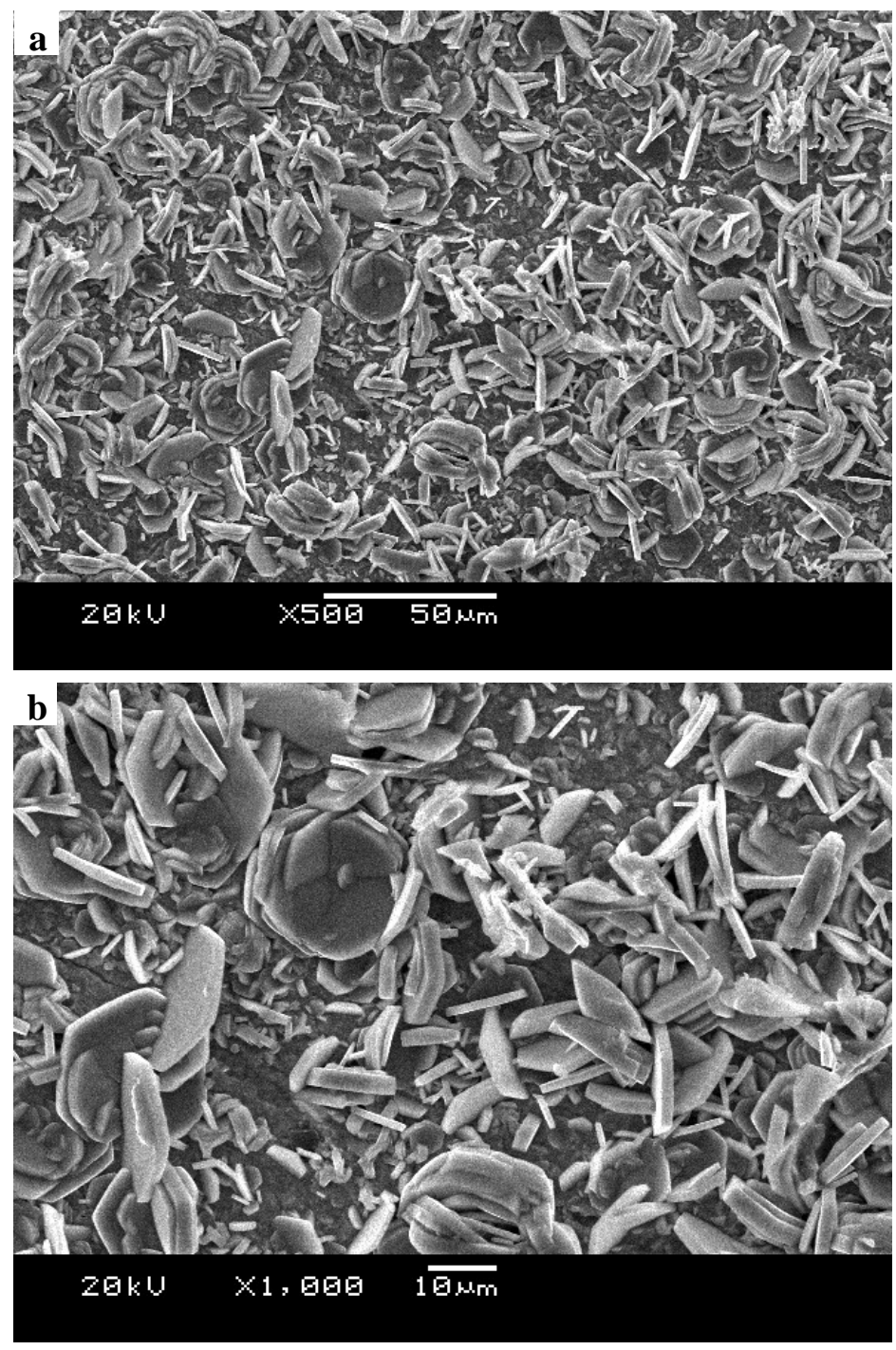

Figure S2. SEM images of $\left(\mathrm{NH}_{4}\right)_{2} \mathrm{Cu}\left(\mathrm{MoO}_{4}\right)_{2}$ crystals on a copper foil substrate (experimental conditions: $1.0 \mathrm{~mL} \mathrm{Na}_{2} \mathrm{MoO}_{4}(0.2 \mathrm{M})+1.0 \mathrm{~mL}$ formamide $+3.0 \mathrm{~mL} \mathrm{H}_{2} \mathrm{O}$, at : $35{ }^{\circ} \mathrm{C}$ for 2 days). (a) Low magnification view. (b) High magnification view. 

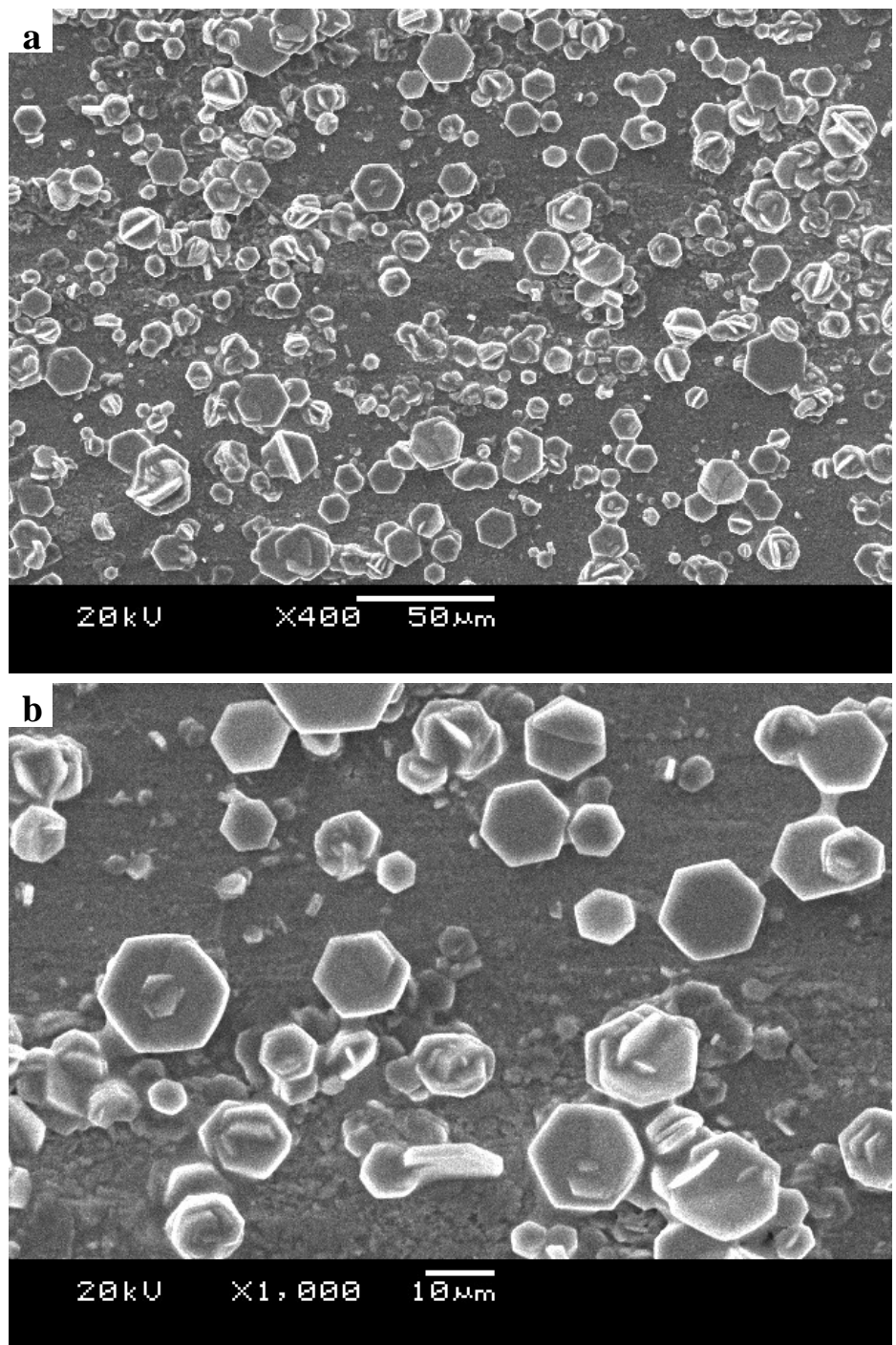

Figure S3. SEM images of $\left(\mathrm{NH}_{4}\right)_{2} \mathrm{Cu}\left(\mathrm{MoO}_{4}\right)_{2}$ crystals on a copper foil substrate (experimental conditions: $1.0 \mathrm{~mL} \mathrm{Na}{ }_{2} \mathrm{MoO}_{4}(0.2 \mathrm{M})+1.0 \mathrm{~mL}$ formamide $+3.0 \mathrm{~mL} \mathrm{H}_{2} \mathrm{O}$, at $50{ }^{\circ} \mathrm{C}$ for 2 days). (a) Low magnification view. (b) High magnification view. 


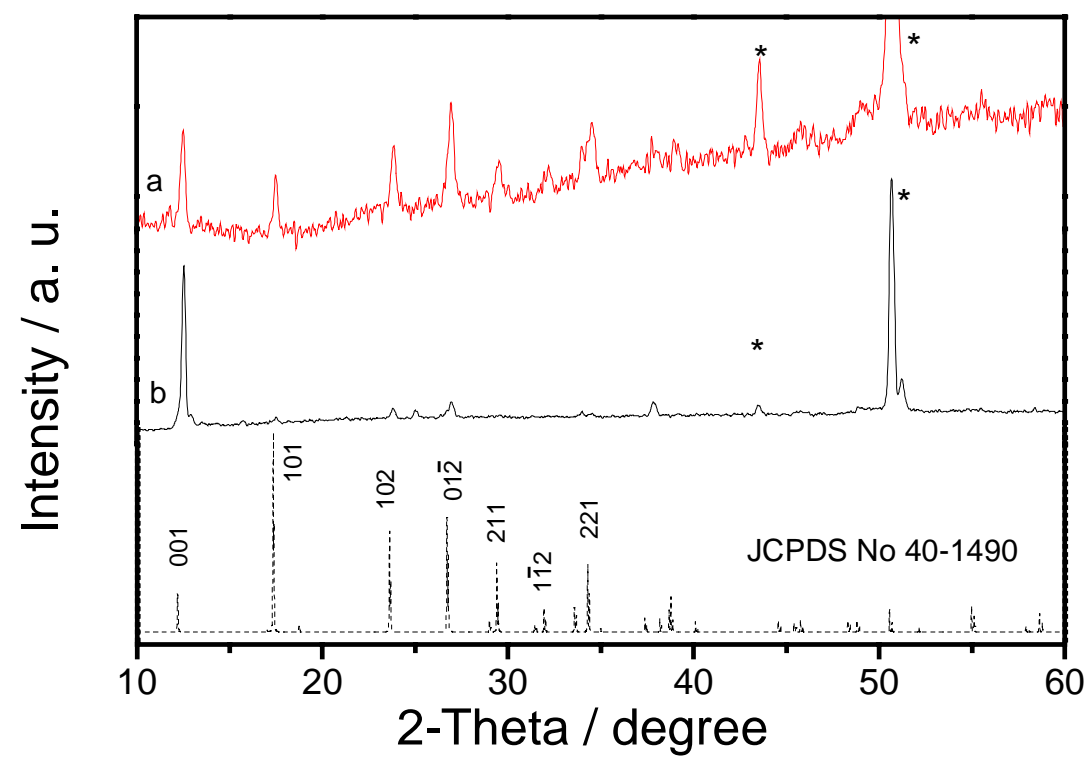

Figure S4. XRD patterns of $\left(\mathrm{NH}_{4}\right)_{2} \mathrm{Cu}\left(\mathrm{MoO}_{4}\right)_{2}$ crystals on copper substrate with a high surface coverage. The solid curve is the experimental XRD pattern; the dashed curve is the simulated one, which is taken from the data in JCPDS card No. 40-1490, the strong reflection peaks generated by the $\mathrm{Cu}$ substrate are marked as *. (a) Experimental conditions correspond to Figure S2. (b) Experimental conditions correspond to Figure S3.

The relative intensities of peaks in Figures S4a and S4b are obviously different. The relative intensities of (001) peak provide information regarding the crystal orientation against the substrate, since the powder diffractometer collects reflections only from the crystallographic planes parallel to the substrate. ${ }^{[3 \mathrm{~b}-3 \mathrm{~d}]}$ For example, XRD patterns (Figure S4a) of triclinic crystals show a weak intensity of (001) plane comparing to Figure S4b, since the hexagonal flakes are seldom oriented along $\{001\}$ planes parallel to the substrate as shown in the typical SEM images (Figure S2 is different from Figure S3). However, Figure S4b shows a strong intensity of (001) plane and weak intensity of (101), (102), and (012) peaks, which means that these hexagonal flakes are dominantly oriented with the (001) planes parallel to the substrate (as shown in Figure S3). From the relative intensity of different reflection peaks, we can conclude that the surface of the lamellar $\left(\mathrm{NH}_{4}\right)_{2} \mathrm{Cu}\left(\mathrm{MoO}_{4}\right)_{2}$ crystals is dominated by (001) crystallographic plane, which means that these flakes form the face with (001) crystallographic plane. 


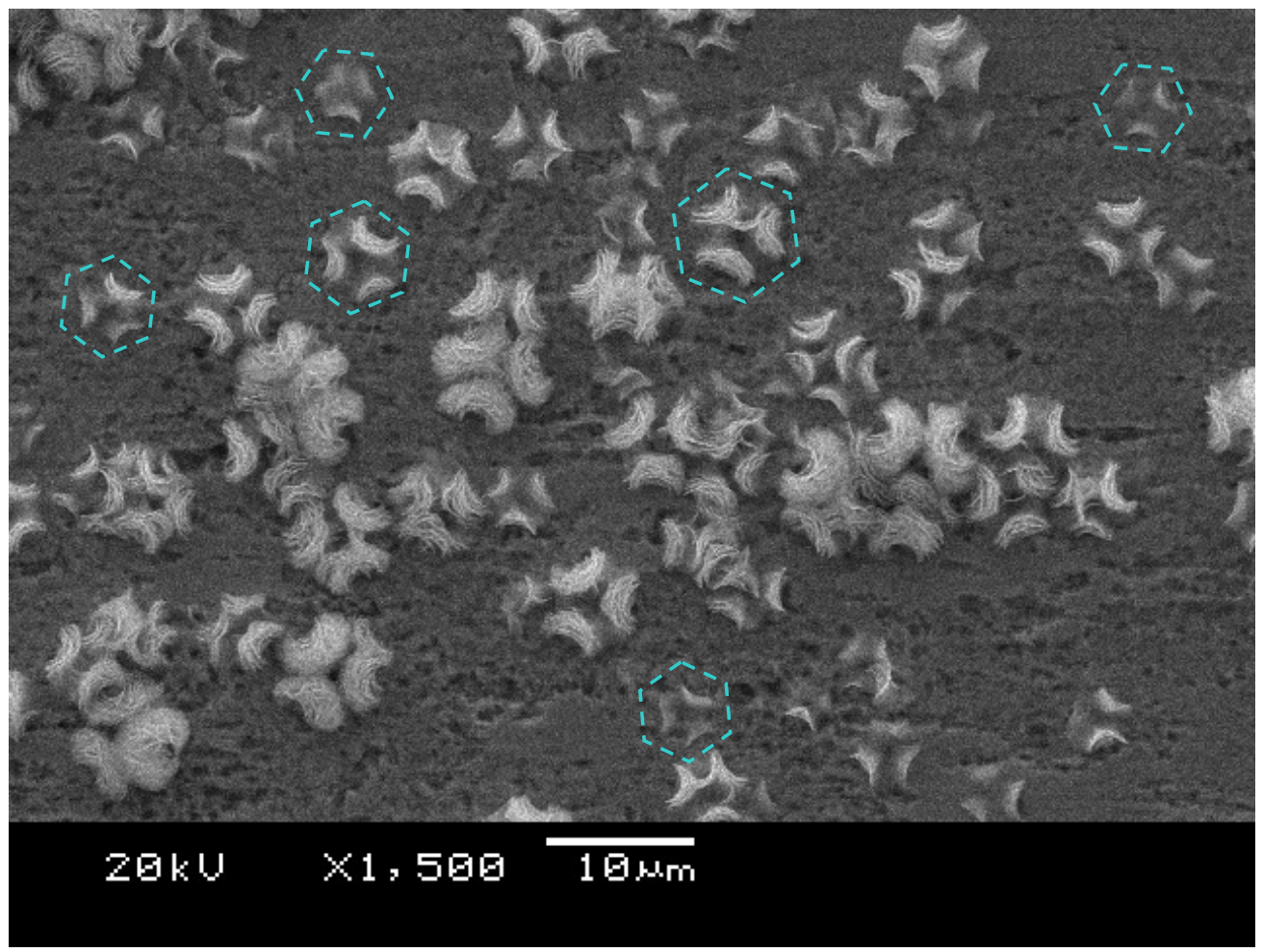

Figure S5. SEM image of $\left(\mathrm{NH}_{4}\right)_{2} \mathrm{Cu}\left(\mathrm{MoO}_{4}\right)_{2}$ crystals on a copper foil substrate (experimental conditions are the same as those shown in Figure 4a), which is a large-scale observation of Figure 4a (some of them are indicated by the dashed hexagons). 

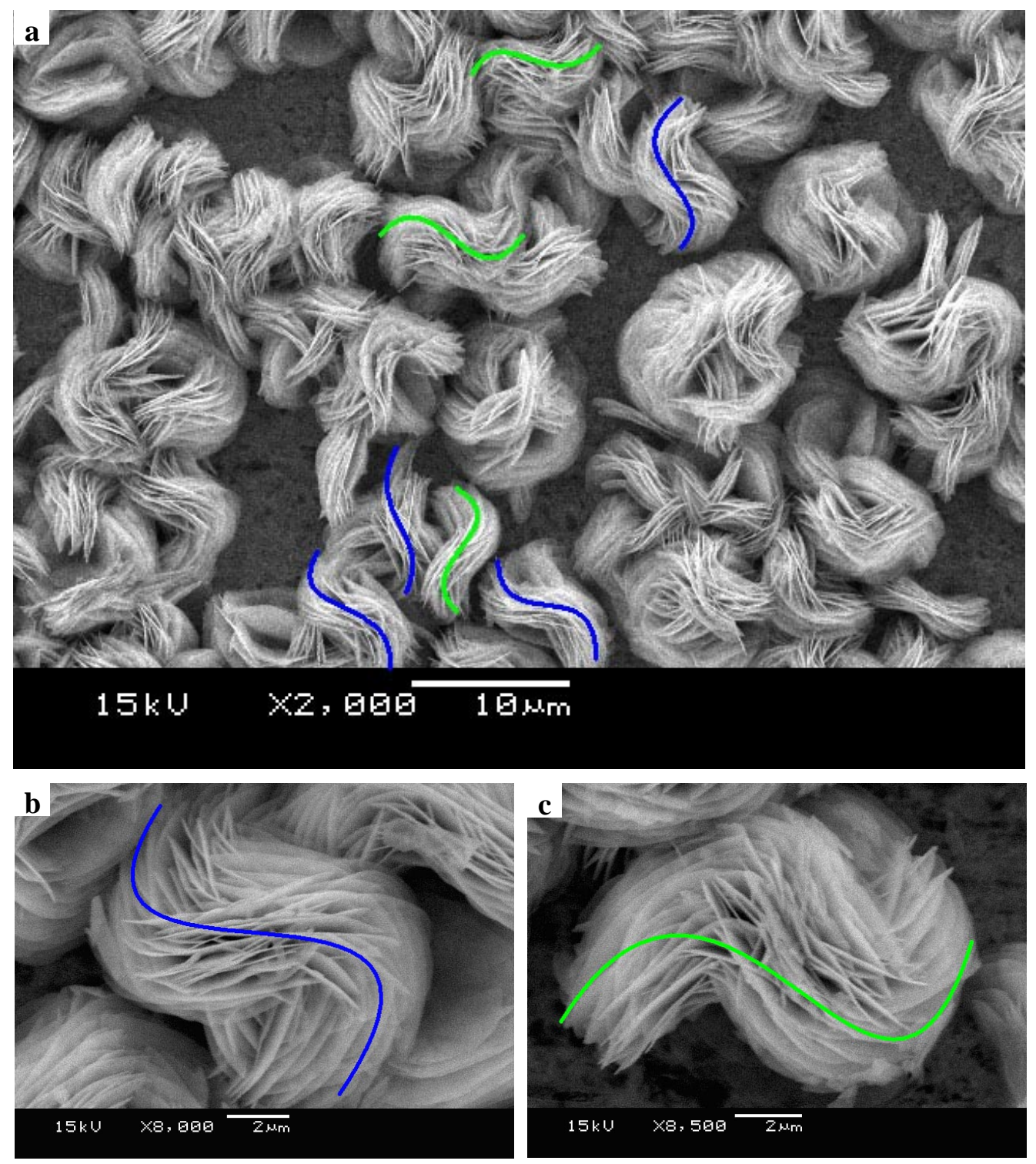

Figure S6. SEM images of $\left(\mathrm{NH}_{4}\right)_{2} \mathrm{Cu}\left(\mathrm{MoO}_{4}\right)_{2}$ crystals on a copper foil substrate (experimental conditions are the same as those shown in Figure5). (a) Panoramic morphologies. (b and c) "S" and “ $\boldsymbol{Q}$ ” structures in high magnification views, which shows a left- and right-hand mirror symmetry. Blue curve represents "S" structures; green curve represents " 2 " structures. 

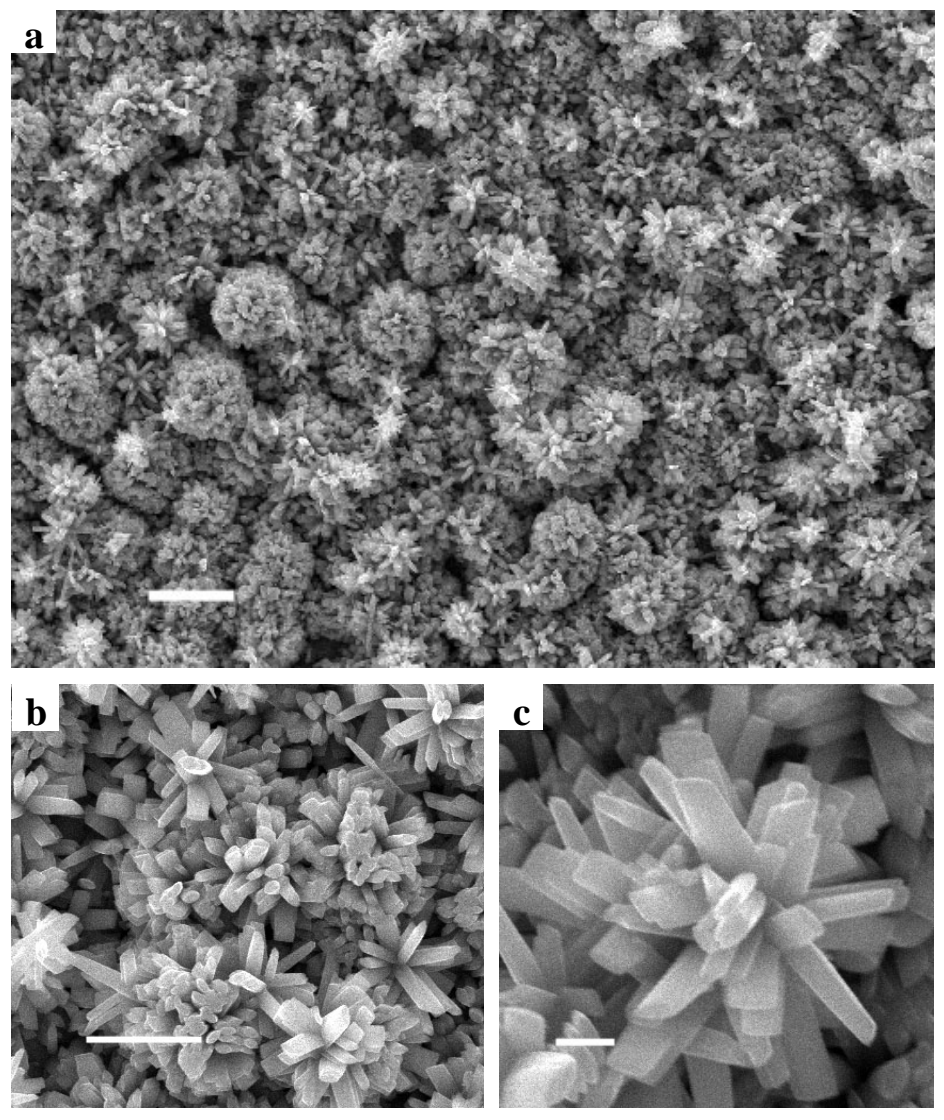

Figure S7. SEM images of $\left(\mathrm{NH}_{4}\right)_{2} \mathrm{Cu}\left(\mathrm{MoO}_{4}\right)_{2}$ crystals on a copper foil substrate, which shows a hierarchical flower-like architecture with the rod-like subunit (experimental conditions: $4.0 \mathrm{~mL} \mathrm{Na} \mathrm{MoO}_{4}(1.0 \mathrm{M})+1.0 \mathrm{~mL}$ formamide, at room temperature for 6 days). (a) Low magnification view, scale bar $=10 \mu \mathrm{m}$. (b and c) High magnification view, scale bar $=5$ and $1 \mu \mathrm{m}$, respectively. 

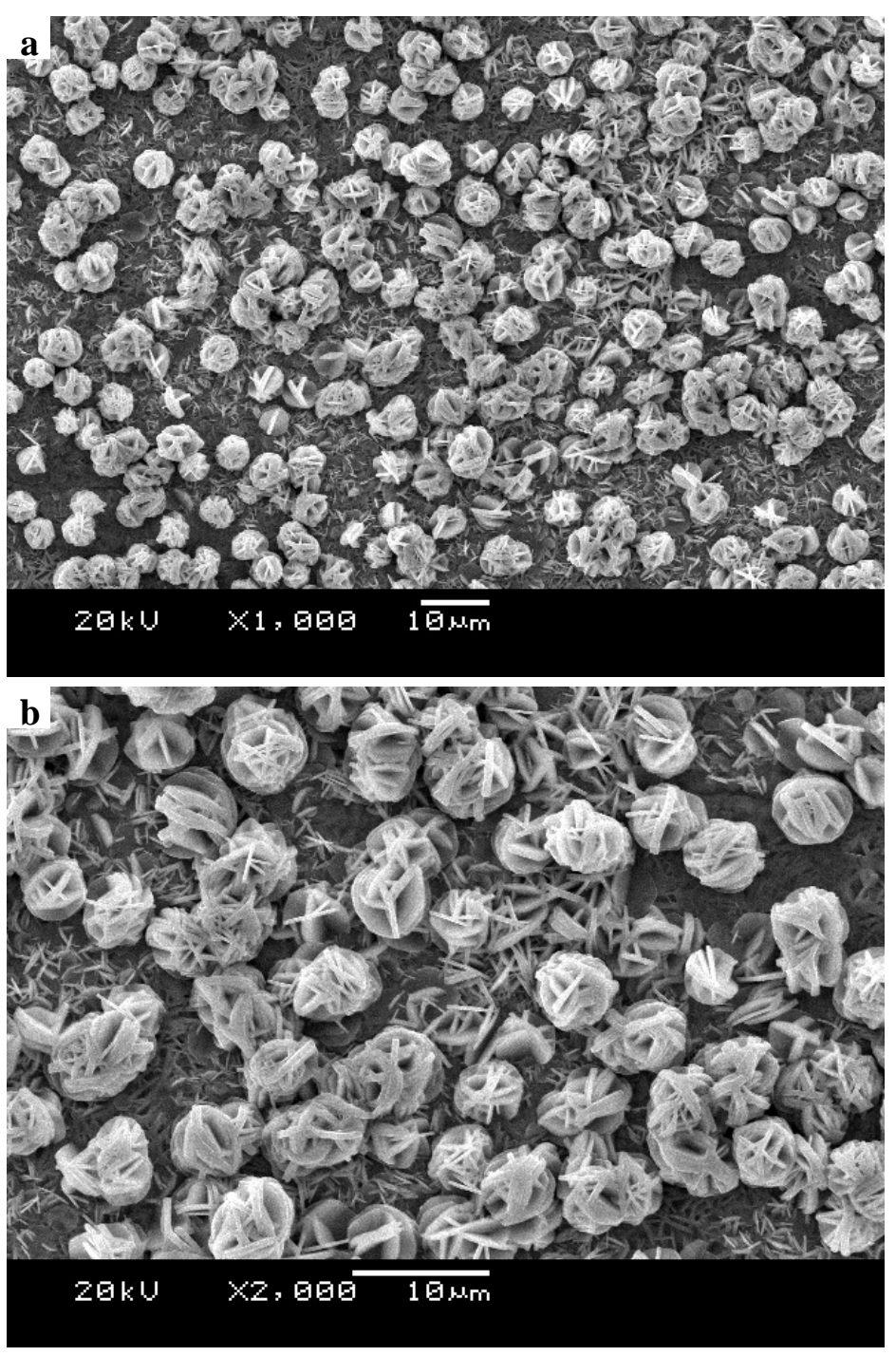

Figure S8. SEM images of $\left(\mathrm{NH}_{4}\right)_{2} \mathrm{Cu}\left(\mathrm{MoO}_{4}\right)_{2}$ crystals on a copper foil substrate (experimental conditions: $1.0 \mathrm{~mL} \mathrm{Na}_{2} \mathrm{MoO}_{4}(0.2 \mathrm{M})+1.0 \mathrm{~mL}$ formamide $+2.0 \mathrm{~mL} \mathrm{H}_{2} \mathrm{O}+$ $1.0 \mathrm{~mL}$ ethanol, at room temperature for 6 days). (a) Low magnification view. (b) High magnification view.

The existence of ethanol can inevitable lead to an increase in the supersaturation of the solution and results in an increase in crystal growth rate. Therefore, the flakes are straight (Figure S8), which have the similarity with the increase of the reaction temperature (the flakes are also straight, comparing Figure S8 to Figures S2 and S3). 


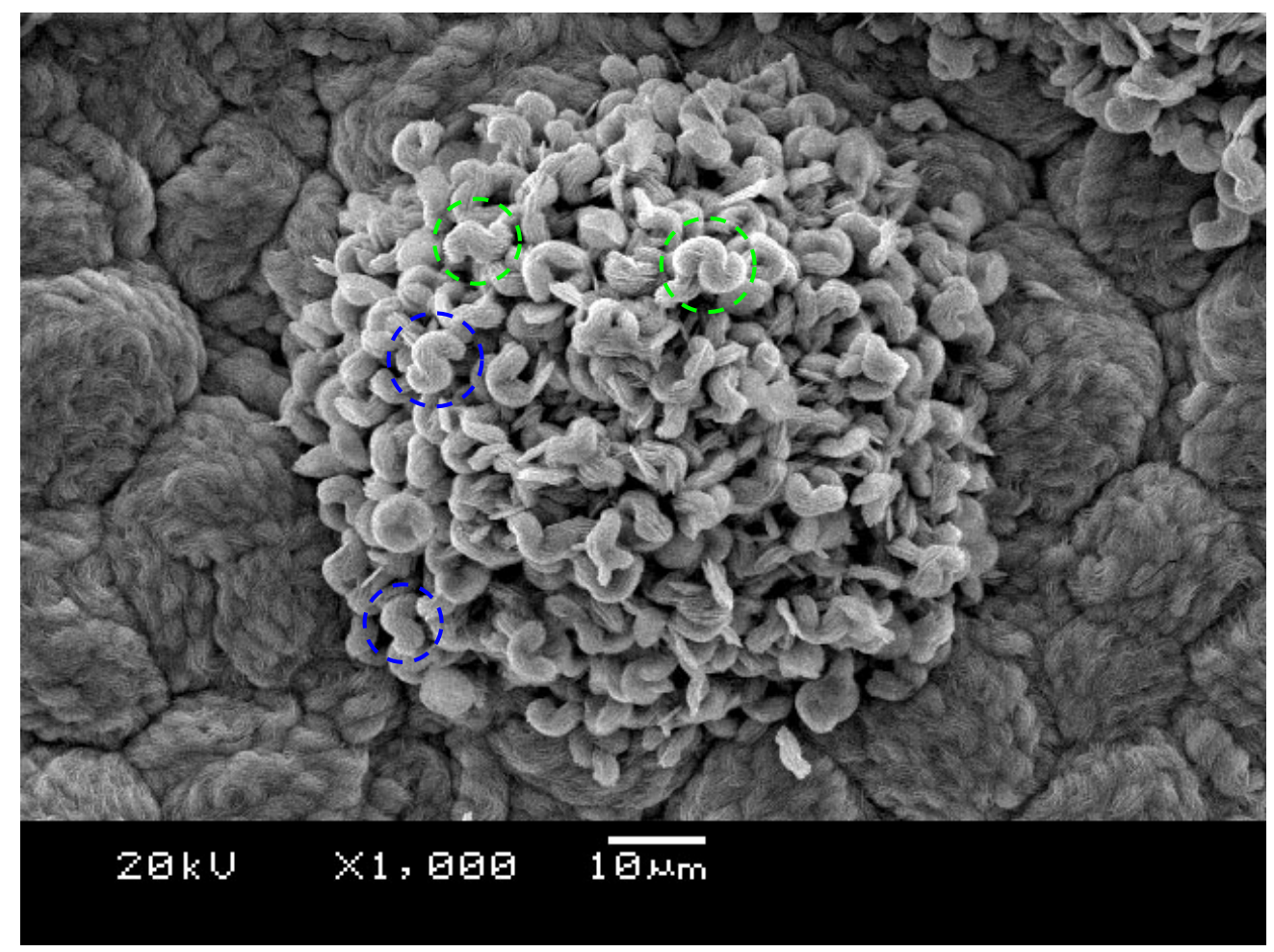

Figure S9. SEM image of $\left(\mathrm{NH}_{4}\right)_{2} \mathrm{Cu}\left(\mathrm{MoO}_{4}\right)_{2}$ hierarchical sphere-like architectures on a copper foil substrate (experimental conditions are the same as those shown in Figure 7), which is a high-magnification view of Figure $7 \mathrm{~b}$. Blue circle indicates " $\mathbf{S}$ " structures; green circle indicates " $\mathrm{Z}$ " structures. 


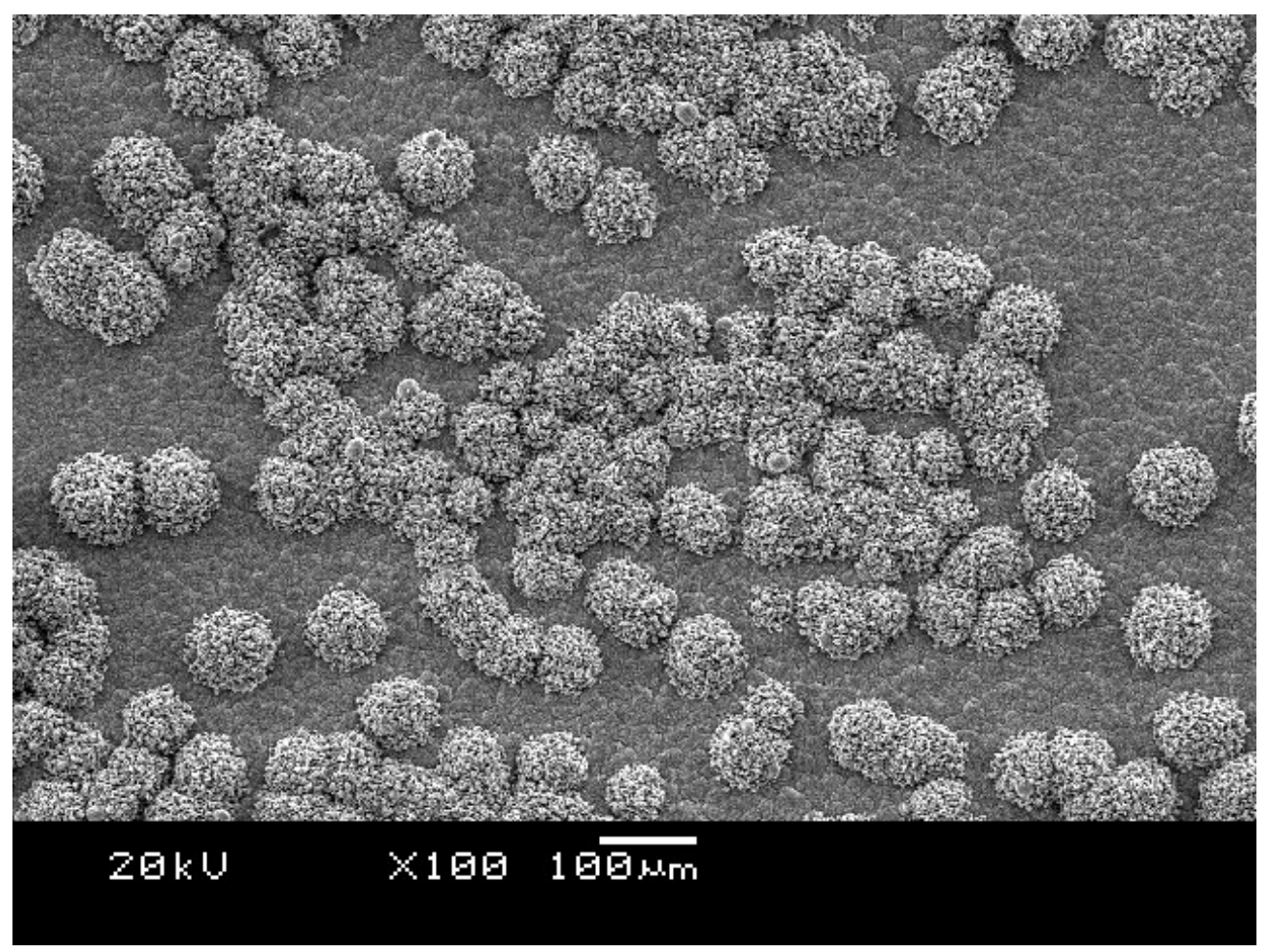

Figure S10. SEM image of $\left(\mathrm{NH}_{4}\right)_{2} \mathrm{Cu}\left(\mathrm{MoO}_{4}\right)_{2}$ hierarchical sphere-like architectures on a copper foil substrate (experimental conditions are the same to those shown in Figure 7), which is a large-scale observation of Figure 7. 

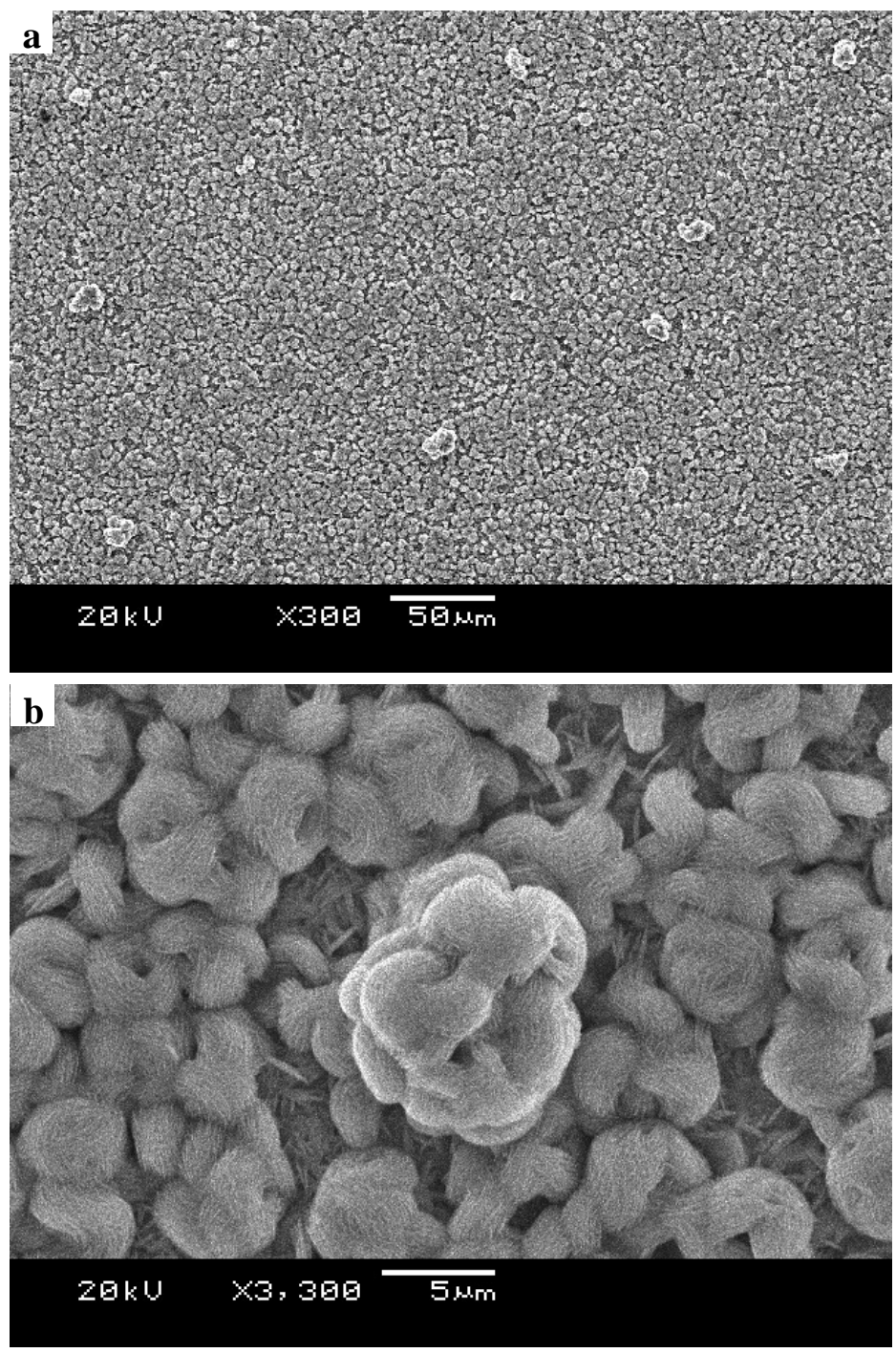

Figure S11. SEM images of $\left(\mathrm{NH}_{4}\right)_{2} \mathrm{Cu}\left(\mathrm{MoO}_{4}\right)_{2}$ hierarchical sphere-like architectures on a copper foil substrate (experimental conditions: $1.0 \mathrm{~mL} \mathrm{Na} \mathrm{MoO}_{4}(0.2 \mathrm{M})+1.0 \mathrm{~mL}$ formamide $+3.0 \mathrm{~mL}$ glucose $(0.1 \mathrm{M})$, at room temperature for 7 days). (a) Low magnification view. (b) High magnification view. 